\title{
The Role of Nkx3.1 in Cancers and Stemness
}

\author{
Ainsley Mike Antao ${ }^{1}$, Suresh Ramakrishna, ${ }^{1,2}$, Kye-Seong Kim ${ }^{1,2}$ \\ ${ }^{1}$ Graduate School of Biomedical Science and Engineering, Hanyang University, Seoul, Korea \\ ${ }^{2}$ College of Medicine, Hanyang University, Seoul, Korea
}

The well-known androgen-regulated homeobox gene, NKX3.1, is located on the short arm of chromosome 8 . It is the first known prostate epithelium-specific marker, and is a transcription factor involved in development of the testes and prostate. In addition to specifying the prostate epithelium and maintaining normal prostate secretory function, Nkx3.1 is an established marker for prostate cancer. Over the years, however, this gene has been implicated in various other cancers, and technological advances have allowed determination of its role in other cellular functions. Nkx3.1 has also been recently identified as a factor capable of replacing Oct4 in cellular reprogramming. This review highlights the role of this tumor suppressor and briefly describes its functions, ranging from prostate development to maintenance of stemness and cellular reprogramming.

Keywords: Cellular reprogramming, CARNs, Prostate development, Prostate cancer

\section{Introduction}

The NKX3.1 homeobox gene is located on human chromosome 8 and encodes a 234 amino acid protein whose functions are critical for embryogenesis as well as oncogenesis (1). Nkx3.1 is a putative prostate tumor suppressor and the earliest known marker of prostate formation during murine development, and its homolog in Drosophila

Received: July 27, 2020, Revised: November 17, 2020,

Accepted: December 14, 2020, Published online: February 28, 2021 Correspondence to Suresh Ramakrishna

Graduate School of Biomedical Science and Engineering, Hanyang University, 222 Wangsimini-ro, Seongdong-gu, Seoul 04763, Korea Tel: +82-2-2220-2424, Fax: +82-2-2220-2422

E-mail: suresh.ramakris@gmail.com

Co-Correspondence to Kye-Seong Kim

Graduate School of Biomedical Science and Engineering, Hanyang University, 222 Wangsimini-ro, Seongdong-gu, Seoul 04763, Korea Tel: +82-2-2220-0607, Fax: +82-2-2220-2422

E-mail: ks66kim@gmail.com

(a) This is an open-access article distributed under the terms of the Creative Commons Attribution Non-Commercial License (http://creativecommons.org/ licenses/by-nc/4.0/), which permits unrestricted non-commercial use, distribution, and reproduction in any medium, provided the original work is properly cited.

Copyright (c) 2021 by the Korean Society for Stem Cell Research is bagpipe (2). Nkx3.1 is expressed during all stages of prostate differentiation and is expressed largely in a prostrate- and androgen-specific manner, restricted to the luminal cells of the prostate gland (3). Loss of Nkx3.1 expression leads to defects in prostatic protein secretion and duct morphogenesis, and contributes to prostate carcinogenesis. Nkx3.1 expression is commonly lost in prostate carcinomas and prostatic intraepithelial neoplasia due to deletion of alleles, promoter methylation, or post-transcriptional silencing $(1,4)$.

The prostrate serves as the first line of defence against foreign pathogens originating from the male reproductive system. Prostatic inflammation acts as a marker for a clinical condition called prostatitis as well as prostate cancer (PCa) $(5,6)$. Prostatitis can be triggered by several factors including pathogens, chemical or mechanical trauma and diet (6). Prostatic inflammation is often accompanied by infiltration of specific immune cells into the prostrate, and their presence is associated with increased cancer risk and poor prognosis (7-9). Maintenance of the prostate and other male reproductive organs is the function of androgens such as testosterone and $5 \alpha$-dihydrotestosterone (DHT) (10). The key effects of androgens, in addition to promoting normal physiological processes, include the initiation, 
development, and growth of prostate cancer (PCa) (11). $\mathrm{Nkx} 3.1$ plays a role in regulating transcription of the androgen receptor (AR) and thus favouring PCa cell survival (12). It is also active in non-prostate tissues and in regulating stemness. It has been identified in a rare population of luminal epithelial cells called CARNs (Castration-resistant Nkx3.1-expressing cells) that possess stem cell properties in prostate regeneration. It has also been shown to act as a transcription factor regulating Oct4 during reprogramming. Oct4 functions as a master regulator maintaining pluripotency and in the generation of induced pluripotent stem cells (iPSCs) (13). The substitution of the oncogenic Oct4 by a tumor suppressor has opened up multiple avenues of research that could be beneficial in the clinical application of these iPSCs.

This review therefore focuses on the role of $\mathrm{Nkx} 3.1$ as a transcription factor in various cellular functions including prostate development and cancers. The unconventional role of $\mathrm{Nkx} 3.1$ in regulating stemness and its novel function during the reprogramming of iPSCs is also considered in this review.

\section{Structural Features of Nkx3.1}

Nkx3.1 is a 234 amino acid protein that contains structural motifs mediating its interactions with other proteins and DNA. These motifs influence the function and stability of the Nkx3.1 protein. The three major regions of Nkx3.1 are the N-terminal region, corresponding to amino acids 1-123; the homeodomain region, corresponding to amino acids 124-183; and the C-terminal region, corresponding to amino acids $184-234$ as depicted in Fig. 1A (14). Many of its amino acid are subject to post-translational modification and play unique roles in the functionality of $\mathrm{Nkx} 3.1$. Some of the features of this gene are discussed here.

Nkx3.1 has been reported to be regulated at the transcriptional level by several factors. Regulation by androgens is mediated by two androgen response elements (AREs) in the 3' UTR region (15).

ETS1 and Sp1 have also been reported to regulate the expression of this gene by binding to the 5' promoter (16, 17). Its transcriptional activity is also regulated by Wnt signalling through a positive regulatory loop that plays an important role in prostate bud growth and luminal epi-

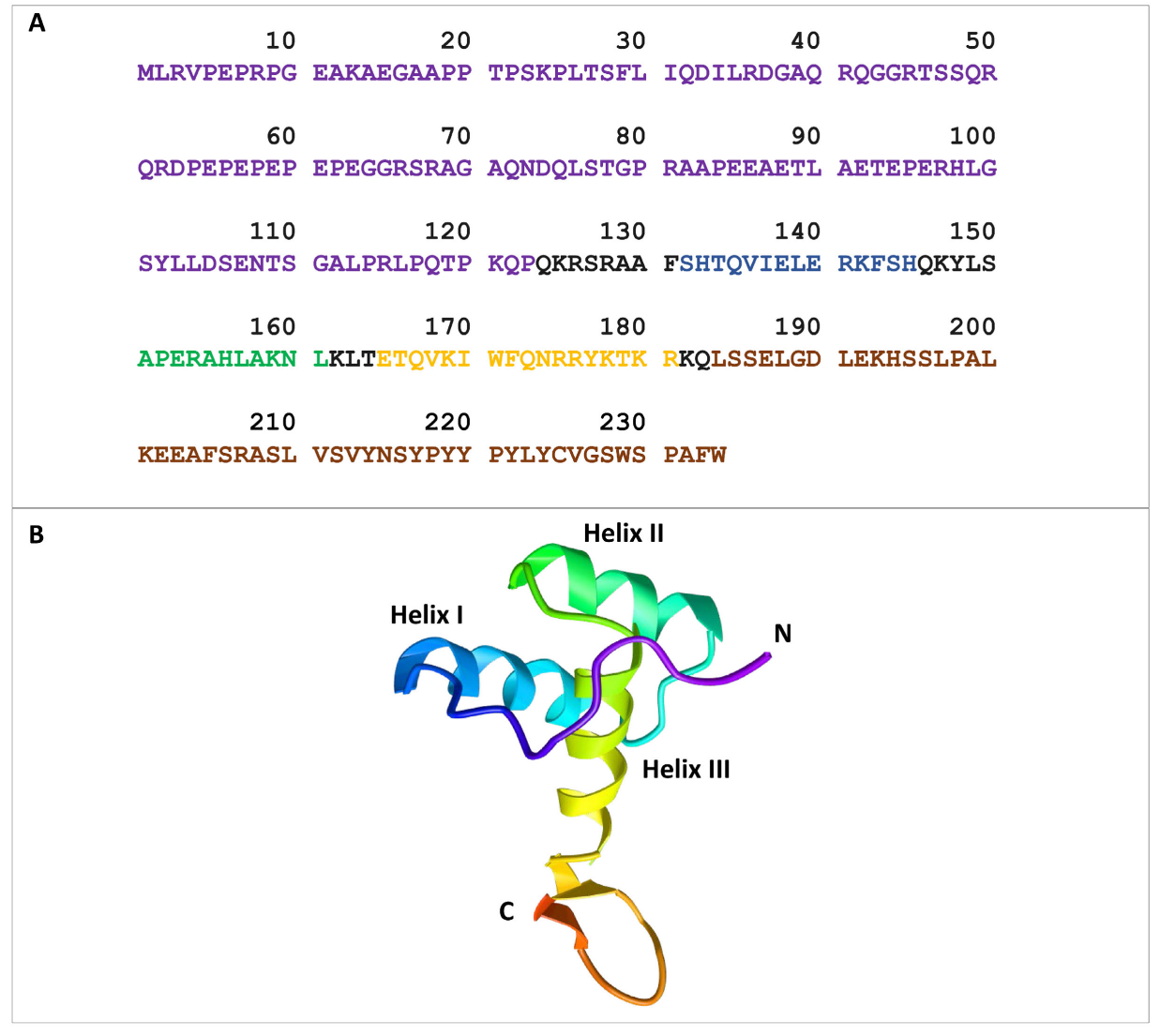

Fig. 1. Structural features of the homeobox protein $\mathrm{Nkx3.1}$. (A) Nkx3.1 is a 234 amino acid protein that contains three major structural motifs crucial for its interactions with other proteins and DNA. Amino acids 1-123 correspond to the $\mathrm{N}$ terminal region and are depicted in purple. The homeodomain region corresponds to amino acids 124-183 and contains three helices, Helix I depicted in blue, Helix II in green and Helix III in yellow. The $\mathrm{C}$ terminal region corresponds to amino acids 184-234, depicted in brown. (B) Nkx3.1 protein structure. The structural feature of Nkx3.1 protein have been identified by nuclear magnetic resonance spectroscopy $(22,23)$. The $\mathrm{N}$ terminal is depicted in purple, Helix I in blue, Helix II in green, Helix III in yellow and the $\mathrm{C}$ terminal in brown. 
thelial differentiation (18). Selective CpG methylation at the Nkx3.1 promoter has been linked to diminished expression of Nkx3.1 in PCa, and evidence has been found suggesting an inverse correlation between MYC and Nkx3.1 levels during PCa progression $(19,20)$.

Divergent amino acid residues around the Nkx homeodomain contribute to the differential DNA binding specificity of members of the Nkx homeobox family, which characteristically contain a tyrosine residue at position 54 of the homeodomain. The Nkx3.1 homeodomain forms three $\alpha$-helices. The first two generate the parallel scaffold, which stabilizes the third helix, perpendicular to them, which contacts the major groove of DNA (21). The structural features of the Nkx3.1 homeobox protein are depicted in Fig. 1 (22, 23). Nkx3.1 has been shown to have a binding preference for the consensus sequence 5'TAAGTA- 3' over 5'-TAAGTG- 3' (24).

\section{Post-Translational Regulation of Nkx3.1}

Nkx3.1 is regulated at the gene level as well as at post-translational levels. The stability of the NKX3.1 gene product is influenced by modification of the homeodomain and flanking regions. Mutations of threonine to alanine at positions 89 and 93 in the N-terminal flanking region reduce its half-life by 50\% (25). Protein kinase CK2 is responsible for phosphorylating these threonine residues and prolonging half-life (25). In contrast, at the C-terminal, phosphorylation of serine 185 controls the ubiquitination and degradation of the protein, and mutation of serine 185 to alanine prolongs half-life (26). Inflammatory cytokines such as TNF- $\alpha$ induce phosphorylation of serines 195 and 196 (27). Nkx3.1 expression is reduced in inflammatory cell-containing tissues and this effect appears to be related to the accelerated ubiquitination and degradation of Nkx3.1 due to TNF- $\alpha$ and IL-1 $\beta$ observed in vitro $(26,27)$. Serine-48-mediated phosphorylation is also critical in Nkx3.1 and has been shown to be affected by the status of the arginine at residue 52, which is a common target for genetic polymorphism. C145T polymorphism causes a non-conservative R52C amino acid replacement that decreases phosphorylation at serine 48 and impairs DNA binding in vitro (28).

Nkx3.1 also undergoes ubiquitination by TOPORS, a RING-finger E3 ligase (29). Topoisomerase I and TOPORS are together responsible for the DNA-unwinding activity of $\mathrm{Nkx} 3$; both are expressed in the prostate, making TOPORS a highly efficient E3 ubiquitin ligase for Nkx3.1 (29-31). In vitro and in vivo experiments have revealed TOPORS-mediated ubiquitination of Nkx3.1. Overex- pression of TOPORS enhanced proteasomal degradation of Nkx3.1 in PCa cells, whereas its knockdown increased Nkx3.1 half-life and steady state level (29). TOPORSmediated ubiquitination is largely targeted via the $\mathrm{Nkx3.1}$ homeodomain, which contains nine lysine residues that can potentially be ubiquitinated, and the N-terminal domain also has some activity (29). The exact site responsible for TOPORS-mediated ubiquitination is yet to be established. The homeodomain Lys182 residue plays an important role in Nkx3.1 turnover via PIM1 inhibition; however, the role of TOPORS in this process has not been elucidated (32).

\section{Functions of Nkx3.1}

Although the role of Nkx3.1 dysregulation in PCs has been well documented over the years, much remains to be understood about the functions of this transcription factor.

\section{Nkx3.1 in prostate development and cancer}

The prostate is a male accessory sex gland that supports and promotes male fertility and insemination. It is composed of small exocrine glands that produce a thin, slightly alkaline fluid that is rich in proteins and compounds like citric acid, acid phosphatases, cholesterol, zinc, calcium, and prostate specific antigen (PSA) (33). The human prostate gland is located below the urinary bladder surrounding the prostatic urethra, residing in front of the rectum. It is covered by three separate, distinct fascial layers-prostatic, endopelvic, and denovilliers-and a band of fibromuscular stroma $(34,35)$. The unilobular prostate has been classified into four globular zones, designated transitional, peripheral, fibromuscular, and central $(36,37)$. In contrast, the murine prostate is composed of multiple lobes and arranged at the base of the bladder around the urethra. Based on their anatomical positions, these lobes have been classified as anterior prostate (AP), ventral prostate (VP), dorsal prostate (DP), and lateral prostate (LP), each having a unique secretion pattern, morphology, and histology (38). Even though the murine prostate lobular structure and human prostate zonal architecture share no overall homology, the dorsolateral and anterior lobes in the mouse are similar to the peripheral zone of the human prostate (39).

Formation of the prostate in mice as well as in humans occurs through epithelial budding from the urogenital sinus (UGS), which is a derivative of the hindgut endoderm arising mid-gestation during mammalian development. The UGS also develops into the bulbourethral glands (BUGs) and prostatic urethra (40). The significance of 
Nkx3.1 in prostate development is highlighted by developmental defects in mutant mice leading to downregulation of genes essential for prostate differentiation, reduced ductal branching, decreased secretory protein production, and epithelial hyperplasia and dysplasia in the prostate, accompanied by changes in cellular differentiation and decreased secretory proteins in BUGs (41-43). In mice, expression of Nkx3.1 RNA is first observed at approximately 15.5 days post-coitum (dpc) in the lateral urogenital sinus epithelium (UGE), which precedes formation of the prostate and BUG (41). At the end of gestation, approximately $17.5 \mathrm{dpc}$, prostatic buds emerge at the rostral end of the UGE, and Nkx3.1 expression has been localized to the leading edge of outgrowing prostatic ducts (41). Roles of Wnt and Fgf10 signalling in activating Nkx3.1 expression during prostate organogenesis have been demonstrated by studies using urogenital sinus explant cultures (44-46). Expression of Wnt ligands has been detected in the urogenital mesenchyme and epithelium prior to and during prostate development (47-49). Deletion of $\beta$-catenin resulted in loss or reduction of prostate bud formation, further suggesting a role of Wnt signalling in prostate formation $(46,50) . \beta$-Catenin is required during embryonic prostate growth and branching but is dispensable in normal adult organs. $\beta$-Catenin regulates progenitors in the epithelial buds as well as a discrete network of genes that include c-Myc and Nkx3.1 during development (46).

Nkx3.1 expression is restricted to the luminal epithelium of mature prostate post-ductal canalization and to the UGE caudal ends where the epithelial buds of BUGs develop (41). Expression of Nkx3.1 continues through BUG morphogenesis to the appearance of the mature epithelium (41). Although the initial expression of Nkx3.1 precedes that of androgen receptors (ARs) in the prostatic epithelium, subsequent expression appears to be dependent on androgen signalling (41). Although Nkx3.1 is positively regulated by androgens, it inhibits the expression of the AR, forming an important loop regulating PI3K-AKT signalling pathway activation via an $\mathrm{AR} / \mathrm{PI} 3 \mathrm{~K}$-dependent mechanism (51). Castration-mediated androgen deprivation in mice leads to regression of the prostate and apoptosis of the majority of its luminal cells, as well as loss of Nkx3.1 in the cells that survive $(3,52,53)$. Nkx3.1 null mutant mice display defects in epithelial differentiation, as indicated by altered prostate secretory protein expression, epithelial hyperplasia, and expression of seminal vesicle markers, underlining the importance of this gene during prostate epithelial specification $(41,43)$.

Nkx3.1 is recognized as a tumor suppressor because its expression decreases with progression of $\mathrm{PCa}$, an effect corroborated by immunohistological analysis of human neoplastic prostate epithelium (54). PCa, like other epithelial cancers, arises from precursor lesions called prostatic intraepithelial neoplasia (PIN), which are induced by inflammatory mitogenic factors and ultimately develop into locally invasive disease and metastasis $(55,56)$. PCa initiation has been attributed to a reciprocal relationship between inflammation and the status of the NKX3.1 gene (57). Studies of Nkx3.1 mutant mice have shown that cancer initiation correlates with enrichment of specific immune populations and increased immune-regulatory gene expression together with the finding that human prostate tumors show low Nkx3.1 expression (57). Loss of Nkx3.1 expression reportedly leads to aberrant overexpression of a cohort of cancer-associated genes that include clusterin and quiescin Q6 (58-60). Nkx3.1 further exacerbates inflammation-induced initiation of $\mathrm{PCa}$, as evidenced by enhanced epithelial plasticity and defects in cellular differentiation (57). A gradual decrease of Nkx3.1 expression has been reported in benign prostatic hyperplasia, highgrade prostatic intraepithelial neoplasia (HGPIN), metastases, carcinomas, and pre-invasive and invasive cancer cells $(19,54)$. Although the exact mechanisms underlying complete loss of Nkx3.1 have not been elucidated, there are clearly selective pressures leading to its loss during PCa development.

Numerous genetic, epigenetic, and chromosomal mutations have been linked to specific stages of $\mathrm{PCa}$ progression (61). Human NKX3.1 maps to chromosome 8p21 and is reported to frequently undergo loss of heterozygosity (LOH) in cases of PIN and PCa (62). About 21 germ-line mutations, which correlate with hereditary disease, have been described at this locus while somatic mutations have not been reported. One germ-line mutation is the T164A polymorphism in the NKX3.1 homeodomain, which reduces Nkx3.1 binding to its cognate DNA binding sequence (22). Genome-wide association studies (GWAS) have helped identify single nucleotide polymorphisms in the Nkx3.1 sequence that are markers for PCa susceptibility. For example, a single nucleotide polymorphism in one allele of the 5'UTR led to decreased binding affinity of Nkx3.1 for transcription factor Spl (63). In this variant, target gene expression was altered and there was decreased transcriptional activity at the Nkx3.1 promoter, reducing its expression (63).

Expression of the tumor suppressor PTEN (phosphatase and tensin homolog deleted on chromosome 10) is critical for maintenance of $\mathrm{Nkx} 3.1$ expression in the prostate and is frequently altered in human cancers. PTEN mutations 
have been strongly implicated in PCa development and have been seen in primary PCa as well as metastatic prostate tissues $(64,65)$. Murine gene targeting experiments have revealed an interaction between $\mathrm{Nkx} 3.1$ and PTEN that supresses PCa, and reductions in the levels of the two factors act synergistically to augment prostate neoplasia $(66,67)$. PTEN is a phosphatase for Nkx3.1, which acts to maintain the level of $\mathrm{Nkx} 3.1$ under conditions that induce the degradation of $\mathrm{Nkx} 3.1$ via its phosphorylation (68). Nkx3.1 also plays an important role in modulating the half-life of $\mathrm{p} 53$ by regulating the activity of nuclear MDM2 and HDAC1. Nkx3.1 binds to HDAC1, thereby stimulating the activity and acetylation of p53 by releasing it from p53-MDM2-HDAC1 complexes. The formation of these complexes would otherwise result in p53 degradation. Reduced p53 activity leads to activation of the PI3K/AKT pathway and ultimately stimulates cell proliferation, decreasing cell death and the initiation of $\mathrm{PCa}$ (67).

\section{Nkx3.1 functions in non-prostate tissues}

Nkx3.1 is transiently expressed during organogenesis across a wide range of tissues outside the urogenital system. Expression is most evident in the paraxial mesoderm, where it is localised to the ventral regions of the most caudal eight-to-nine somites and becomes restricted to the sclerotome $(69,70)$. Expression of $\mathrm{Nkx3.1}$ in explant cultures of somites is dependent on the neural tube or notochord and is induced by Sonic Hedgehog (69). Despite the expression of $\mathrm{Nkx} 3.1$ in the newly-formed paraxial mesoderm, Nkx3.1 null mutants do not display any phenotype in sclerotomal derivatives $(70,71)$. Nkx3.1 expression has also been reported in the distal epithelium of the tongue, dorsal aorta, a subset of teeth, the arcuate and interlobular arteries of the kidney, and the dorsal region of Rathke's pouch $(71,72)$.

Nkx3.1 null mutants display only a minor phenotype in the lobular arteries of the kidneys, seen as vacuolation of the arterial walls. No other phenotypes have been observed for other non-urogenital tissues that express $\mathrm{Nkx} 3.1$, including the cerebral cortex, pituitary glands, hippocampus, and hair follicles (42). The only significant nonurogenital phenotype described for Nkx3.1 null mutants occurs within the minor salivary glands of the oral cavity, where there is increased accumulation of mucous secretions accompanied by a significant decrease in ductal branching of the palatine glands $(42,71)$. The prognosis for oral squamous cell carcinoma (OSCC) depends significantly on the presence of cervical lymph node metastasis (LNM), and genome-wide analysis of DNA copy number aberrations (CAN) using data from OSCC patients has shown that expression of NKX3.1, along with several other genes, is significantly correlated with LNM (73). The role of Nkx3.1 in OSCC has been further validated by qRT-PCR and immunohistochemical (IHC) analyses showing reduced $\mathrm{Nkx} 3.1$ expression in occult LNM cases (73). Nkx3.1 expression level is a useful aid in diagnosing salivary duct carcinoma (SDC). However, SDC progression was not correlated with decreased Nkx3.1 expression (74).

Nkx3.1 is an important mediator of bladder fibrosis in bladder outlet obstruction (75). Fibrosis leads to stiffening of healthy tissues and organ dysfunction due to the irreversible remodelling caused by deposition of collagen in the extracellular matrix of various organs. Expression of Nkx3.1 is induced in the bladder following partial bladder outlet obstruction (PO), and is responsible for activation of pathways leading to tissue fibrosis (75). Even though the bladder appears to be functionally and morphologically intact, fibrosis is attenuated in the absence of $\mathrm{Nkx} 3.1$ (75). Nkx3.1 is also a potential therapeutic target for the treatment of nasopharyngeal carcinoma (NPC), along with cyclin B2 (CCNB2) (76). NPC tumors arise from the epithelial cells covering the surface and lining of the nasopharynx, and gene expression profiling of NPC identified NKX3.1 as a down-regulated and CCNB2 as an up-regulated gene; in agreement with this, overexpression of Nkx3.1 led to loss of NPC cell viability, and invasiveness (76).

\section{Nkx3.1 and stemness}

The activities and regulation of adult epithelial stem cells can be studied in the prostate system, which provides contexts for examining changes due to cancer development and tissue regeneration. Three differentiated cell types exist in prostate epithelium: basal cells, luminal secretory cells, and neuroendocrine cells (77). Absence of androgens results in rapid apoptosis of approximately $90 \%$ of luminal cells. However, a small, number of basal cells are stably maintained in the regressed state (78). Re-administration of androgens results in regeneration of the prostate epithelium, implying the presence of a population of stem cells $(79,80)$. A role of $\mathrm{Nkx3} .1$ as a stemness-regulating factor was first suggested by Wang et al. (53), who by lineage-tracing identified a population of rare luminal cells that expressed $\mathrm{Nkx} 3.1$ even in the absence of testicular androgens. These bipotential, self-renewing cells, which could regenerate prostate ducts in renal grafts, were called castration-resistant Nkx3.1-expressing cells or CARNs (53). When CARNs were marked in genetically-engineered 
mouse lines using an inducible $\mathrm{Cre}^{\mathrm{ERT} 2}$ recombinase under the control of the endogenous Nkx3.1 promoter. Cre activation in castrated $N k \times 3.1^{\mathrm{CreERT2/+}} ; \mathrm{R} 26 \mathrm{R}-\mathrm{YFP}^{\mathrm{l}}$ male mice by tamoxifen led to yellow fluorescent protein (YFP) expression in luminal epithelial cells that corresponded to lineage-marked CARNs. All luminal cells, as well as a small percentage of basal cells, normally express $\mathrm{Nkx} 3.1$ in the hormonally-intact adult prostate, whereas only the rare luminal CARNs express Nkx3.1 in regressed epithelium (81). The multipotent nature of CARNs was also demonstrated by transplantation of single lineage-marked CARNs into the kidney, which resulted in the formation of prostatic ducts containing all three prostate epithelial cell types (53).

Two possible functions have been proposed for the CARNs in prostate epithelium (81). One model assumes the co-existence of basal as well as luminal stem cells within the prostate epithelium, with CARNs representing the luminal stem cells. According to the other model, CARNs are facultative stem cells that correspond to luminal progenitors, and acquire stem cell properties after androgen deprivation (81). These models imply different roles for CARNs as 'cells of origin' in PCa. 'Cell of origin' models posit the initiation of tumorigenesis from a normal tissue cell that retains the ability to self-renew and generates different cell lineages within tumors. CARNs maintained stem-like properties and expressed markers such as Sox2, Nanog, Oct4 and ALDH1A1 associated with stemness in an established human xenograft model (82). Besides Nkx3.1-expressing CARNs, other forms of cancer stem cell (CSC) have been identified that give rise to castration-resistant prostate cancers (CRPC). One such example includes cancer-associated fibroblasts (CAF) (83-85).

Another role of Nkx3.1 has been recently elucidated, namely as a replacement for Oct4 in stem cell reprogramming (86). Originally, Takahashi and Yamanaka (87) identified four factors capable of reprogramming differentiated cells back to stem cells -Oct4, Sox2, Klf4, and Myc (OSKM), collectively known as Yamanaka factors. Viralmediated transduction of the Yamanaka factors has provided a major technique for generating induced pluripotent stem cells (iPSCs)- since that time (88). However, activation of an endogenous pluripotency program can create a barrier to reprogramming (89), and overexpression of oncogenic transcription factors during somatic reprogramming poses a risk of malignant transformation, which limits their use in a clinical setting (90). Various groups have attempted to replace or omit some of the reprogramming factors in order to understand the molecular role of each factor (91-94). Others have attempted to use small molecule compounds as substitutes (91, 95, 96). One of these strategies, replacement or omission of Oct4, has gained a lot of attention (86). As an alternative to omitting oncogenes during reprogramming, the use of tumor suppressor genes such as p53, p16 and Rb1 as regulators of cell reprogramming is well established (90, 97-99). The process of reprogramming has usually been associated with deletion of tumor suppressor genes and duplication of oncogenes (100), and the tumor suppressor p53 has been reported to act as a barrier to reprogramming. However, iPSCs generated by incorporating an extra copy of the p53 locus were found to retain normal pluripotency and to have reduced tumorigenic potential in mice (90, 97). Thus, increasing the dosage of tumor suppressors to generate iPSCs may limit their tumorigenicity and increase their clinical applicability (90).

A previously unknown role of the tumor suppressor Nkx3.1 was revealed by using a heterokaryon reprogramming system generated by fusing human fibroblasts and mouse embryonic stem cells (ESCs) (86). This system was used to generate molecular maps of early reprogramming by RNA-seq at time points over the first 24 hours post fusion. Techniques such as assays for transposase-accessible chromatin by sequencing (ATAC-sequencing) and motif-enrichment analysis then demonstrated a brief period of expression of $\mathrm{Nkx} 3.1$ two to three hours post fusion, at the onset of reprogramming (86). Oct4 and Nanog were reported to be the first to show signs of transcriptional activation one day post-fusion (101). Since Nkx3.1 expression preceded activation of Oct4 the authors proposed that $\mathrm{Nkx3}$.1 was an upstream activator of endogenous Oct4, and this was confirmed by demonstrating presence of $\mathrm{Nkx} 3.1$ at the Oct4 promoter. Further experiments omitting and replacing individual components from the reprogramming cocktail revealed the potential of $\mathrm{Nkx} 3.1$ as a replacement for exogenous Oct4 in human and mouse reprogramming (86).

Reprogramming of fibroblasts using OSKM has revealed that Nkx3.1 acts downstream of the IL6-Stat3 signalling cascade. Expression of $\mathrm{Nkx3} .1$ depends upon IL-6R, which is essential for OSKM reprogramming in both human and mouse fibroblasts. Stat 3 has been reported to play a role in activating $\mathrm{Nkx} 3.1$ as well as Oct4; as shown in Fig. 2A, co-expression of Stat3 and Nkx3.1 rescued colony formation in the absence of Il-6r. When Nkx3.1 was used to replace Oct4 in the Oct4, Sox2, Klf4 (OSK) cocktail the results showed that reprogramming of Nkx3.1, Sox2, Klf4 (NSK)-derived iPSCs were as efficient as that of OSK-derived iPSCs in mice and humans (Fig. 2B). The NSK-derived iPSCs were pluripotent and capa- 


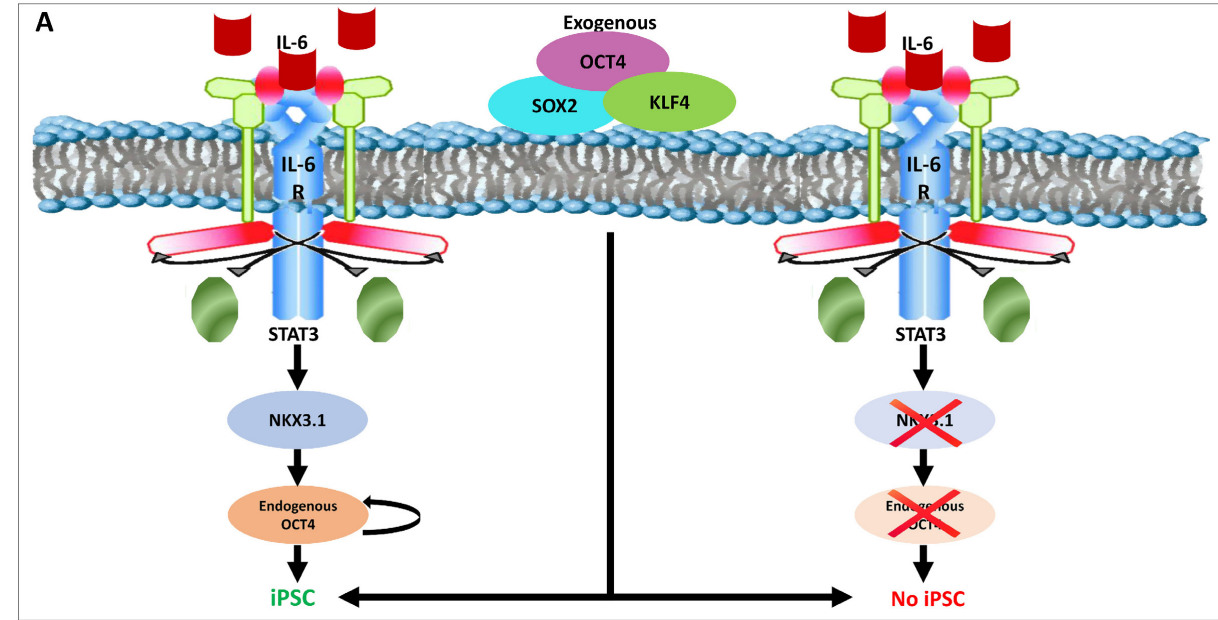

B
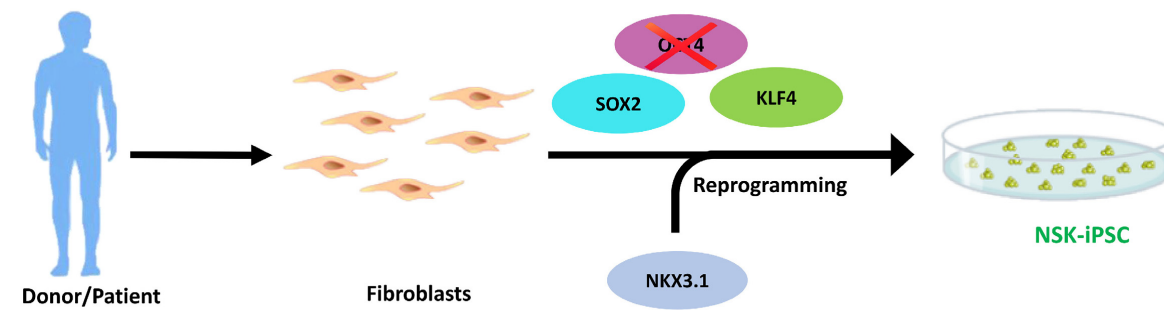

Donor/Patient

Fibroblasts
Fig. 2. The activities of $\mathrm{Nkx3.1}$. (A) The role of Nkx3.1 in the IL-6-STAT3 signalling pathway during iPSC induction. Nkx3.1 is a target of STAT3, downstream of IL6r activation and is essential during reprogramming. IL-6r deficiency during reprogramming is reported to be rescued by $\mathrm{Nkx3.1}$ alone or in cooperation with STAT3. However, knockdown of STAT3 decreases Nkx3.1 protein level, whereas knockdown of $\mathrm{Nkx3.1}$ blocks iPSC reprogramming (86). (B) $\mathrm{Nkx3.1}$ can replace Oct4 in cellular reprogramming, and promotes the generation of iPSCs with a similar efficiency to Oct4. ble of producing cells of all three germ layers (86).

\section{Perspectives}

The androgen-regulated, prostate specific-tumor suppressor, Nkx3.1, plays major roles in controlling epithelial cell growth, cell differentiation, and stem cell maintenance $(41,53,102)$. However, as reviewed in this article, loss of expression of this gene has been widely implicated in the development of PCa and thus serves as a marker for cancer progression $(54,68)$. The clinical relevance of $\mathrm{Nkx} 3.1$ has so far been limited to its use as a marker for PCa progression and it has not been subjected to targeted therapeutic approaches (54). Up-regulation of $\mathrm{Nkx} 3.1$ in vitro in prostate cancer cell lines has revealed some promising anti-cancerous effects, but these have not been transferred to a clinical setting. Up-regulation of $\mathrm{Nkx} 3.1$ using synthetic double stranded ODNs in LNCaP inhibited cell proliferation, while stable expression of $\mathrm{Nkx} 3.1$ inhibited the proliferative and invasive activities of PC-3 $(103,104)$.
Nkx3.1 has been reported to be stabilized by inhibition of dual-specificity tyrosine-regulated kinase 1B (DYRK1B) which regulates $\mathrm{Nkx} 3.1$ via phosphorylation at serine 185 , and inhibition of this kinase in prostate cancer increased the level of $\mathrm{Nkx} 3.1$ thereby proving the kinase to be a potential therapeutic target in prostate cancer (105). Nkx3.1 has also been reported to be regulated via other posttranslational modifications, as reviewed above, and these regulators provide alternative potential anti-cancer therapeutic approaches that require further study.

Besides the huge potential of $\mathrm{Nkx3} .1$ as a therapeutic target, it has also been shown to play a role in CARNs and during iPSC differentiation. The oncogene Oct4 serves as a master regulator in maintaining pluripotency and has been frequently used for generating iPSCs (106-109); iPSC generation is indeed dependent on the direct activation of endogenous Oct4 (110-112). However, the recent identification of $\mathrm{Nkx} 3.1$ as a potential replacement for Oct4 paves the way for future research focused on $\mathrm{Nkx} 3.1$ as a regulator of pluripotency and stem cell differentiation. 
All these findings suggest that $\mathrm{Nkx} 3.1$ may be a transcription factor responsible for the expression of other as yet undefined genes that are activated during reprogramming. Cellular DNA damage repair pathways have also been reported to be activated by $\mathrm{Nkx} 3.1$ and could potentially help maintain the genomic integrity of NSK-derived iPSCs, which promises to be an interesting avenue of investigation (113). Like the tumor suppressor role of Nkx3.1, numerous other genes may have previously overlooked roles that could be identified using similar approaches. Because Nkx3.1 is itself a tumor suppressor gene, its ability to replace Oct4 in iPSC induction has broad implications, especially in the clinical applications of iPSCs.

\section{Conclusions}

$N k \times 3.1$ is well known as a prostate-specific tumor suppressor gene; however, its role has now been expanded to non-prostate tissues. Nkx3.1 is regulated by androgens in normal prostate cells, but this regulation is consistently lost in prostate tumors, and reportedly triggers a cohort of genes that are overexpressed during tumor initiation. Nkx3.1 also plays an important role in early mouse development and is expressed in the mouse embryo as early as day 15.5 dpc. A previously unrecognized role of this prostate-specific gene is in self-renewing prostate luminal cells called CARNs, whose effect points to the possibility that Nkx3.1 is a stemness gene. Further investigation has revealed a role of $\mathrm{Nkx3} .1$ in reprogramming differentiated cells back into iPSCs, thus opening up the prospect that it can activate Oct4 and promote pluripotency.

\section{Acknowledgments}

I would like to thank members of the KSK and Suri laboratories for helpful discussion. This study was supported by grants from the National Research Foundation of Korea (2017M3A9B3061830, 2017M3A9C6061361) and Medical Research Center (2017R1A5A2015395), funded by the National Research Foundation of Korea (NRF) of the Ministry of Science, ICT and Future Planning, Republic of Korea.

\section{Potential Conflict of Interest}

The authors have no conflicting financial interest.

\section{References}

1. Abate-Shen C, Shen MM, Gelmann E. Integrating differentiation and cancer: the Nkx3.1 homeobox gene in prostate organogenesis and carcinogenesis. Differentiation 2008; 76:717-727

2. Kim Y, Nirenberg M. Drosophila NK-homeobox genes. Proc Natl Acad Sci U S A 1989;86:7716-7720

3. Bieberich CJ, Fujita K, He WW, Jay G. Prostate-specific and androgen-dependent expression of a novel homeobox gene. J Biol Chem 1996;271:31779-31782

4. Abdulkadir SA, Magee JA, Peters TJ, Kaleem Z, Naughton CK, Humphrey PA, Milbrandt J. Conditional loss of $\mathrm{Nkx3.1}$ in adult mice induces prostatic intraepithelial neoplasia. Mol Cell Biol 2002;22:1495-1503

5. Sfanos KS, Yegnasubramanian S, Nelson WG, De Marzo $\mathrm{AM}$. The inflammatory microenvironment and microbiome in prostate cancer development. Nat Rev Urol 2018;15:1124

6. Cai T, Santi R, Tamanini I, Galli IC, Perletti G, Bjerklund Johansen TE, Nesi G. Current knowledge of the potential links between inflammation and prostate cancer. Int J Mol Sci 2019;20:3833

7. McArdle PA, Canna K, McMillan DC, McNicol AM, Campbell R, Underwood MA. The relationship between T-lymphocyte subset infiltration and survival in patients with prostate cancer. Br J Cancer 2004;91:541-543

8. Nonomura N, Takayama H, Nakayama M, Nakai Y, Kawashima A, Mukai M, Nagahara A, Aozasa K, Tsujimura A. Infiltration of tumour-associated macrophages in prostate biopsy specimens is predictive of disease progression after hormonal therapy for prostate cancer. BJU Int 2011; 107:1918-1922

9. Strasner A, Karin M. Immune infiltration and prostate cancer. Front Oncol 2015;5:128

10. Keller ET, Ershler WB, Chang C. The androgen receptor: a mediator of diverse responses. Front Biosci 1996;1:d59d71

11. Trapman J, Brinkmann AO. The androgen receptor in prostate cancer. Pathol Res Pract 1996;192:752-760

12. Tan PY, Chang CW, Chng KR, Wansa KD, Sung WK, Cheung E. Integration of regulatory networks by NKX3-1 promotes androgen-dependent prostate cancer survival. Mol Cell Biol 2012;32:399-414

13. Kim KP, Wu Y, Yoon J, Adachi K, Wu G, Velychko S, MacCarthy CM, Shin B, Röpke A, Arauzo-Bravo MJ, Stehling M, Han DW, Gao Y, Kim J, Gao S, Schöler HR. Reprogramming competence of OCT factors is determined by transactivation domains. Sci Adv 2020;6:eaaz7364

14. Padmanabhan A, Rao V, De Marzo AM, Bieberich CJ. Regulating NKX3.1 stability and function: post-translational modifications and structural determinants. Prostate 2016;76:523-533

15. Thomas MA, Preece DM, Bentel JM. Androgen regulation of the prostatic tumour suppressor NKX3.1 is mediated by its 3' untranslated region. Biochem J 2010;425:575-583 
16. Yu CX, Jin T, Chen WW, Zhang PJ, Liu WW, Guan HY, Zhang J, Liu QW, Jiang AL. Identification of Sp1-elements in the promoter region of human homeobox gene NKX3.1. Mol Biol Rep 2009;36:2353-2360

17. Preece DM, Harvey JM, Bentel JM, Thomas MA. ETS1 regulates NKX3.1 5' promoter activity and expression in prostate cancer cells. Prostate 2011;71:403-414

18. Kruithof-de Julio M, Shibata M, Desai N, Reynon M, Halili MV, Hu YP, Price SM, Abate-Shen C, Shen MM. Canonical Wnt signaling regulates Nkx3.1 expression and luminal epithelial differentiation during prostate organogenesis. Dev Dyn 2013;242:1160-1171

19. Asatiani E, Huang WX, Wang A, Rodriguez Ortner E, Cavalli LR, Haddad BR, Gelmann EP. Deletion, methylation, and expression of the NKX3.1 suppressor gene in primary human prostate cancer. Cancer Res 2005;65:11641173

20. Iwata T, Schultz D, Hicks J, Hubbard GK, Mutton LN, Lotan TL, Bethel C, Lotz MT, Yegnasubramanian S, Nelson WG, Dang CV, Xu M, Anele U, Koh CM, Bieberich CJ, De Marzo AM. MYC overexpression induces prostatic intraepithelial neoplasia and loss of Nkx3.1 in mouse luminal epithelial cells. PLoS One 2010;5:e9427

21. Ju JH, Maeng JS, Zemedkun M, Ahronovitz N, Mack JW, Ferretti JA, Gelmann EP, Gruschus JM. Physical and functional interactions between the prostate suppressor homeoprotein NKX3.1 and serum response factor. J Mol Biol 2006;360:989-999

22. Zheng SL, Ju JH, Chang BL, Ortner E, Sun J, Isaacs SD, Sun J, Wiley KE, Liu W, Zemedkun M, Walsh PC, Ferretti J, Gruschus J, Isaacs WB, Gelmann EP, Xu J. Germ-line mutation of NKX3.1 cosegregates with hereditary prostate cancer and alters the homeodomain structure and function. Cancer Res 2006;66:69-77

23. Liu G, Xiao R, Lee HW, Hamilton K, Ciccosanti C, Wang HB, Acton TB, Everett JK, Huang YJ, Montelione GT. Solution NMR structure of Homeobox domain of Homeobox protein Nkx-3.1 from homo sapiens, Northeast Structural Genomics Consortium Target HR6470A. 2011 doi:10.2210/pdb2L9R/pdb

24. Steadman DJ, Giuffrida D, Gelmann EP. DNA-binding sequence of the human prostate-specific homeodomain protein NKX3.1. Nucleic Acids Res 2000;28:2389-2395

25. Li X, Guan B, Maghami S, Bieberich CJ. NKX3.1 is regulated by protein kinase CK2 in prostate tumor cells. Mol Cell Biol 2006;26:3008-3017

26. Markowski MC, Bowen C, Gelmann EP. Inflammatory cytokines induce phosphorylation and ubiquitination of prostate suppressor protein NKX3.1. Cancer Res 2008;68:68966901

27. Bethel CR, Faith D, Li X, Guan B, Hicks JL, Lan F, Jenkins RB, Bieberich CJ, De Marzo AM. Decreased NKX3.1 protein expression in focal prostatic atrophy, prostatic intraepithelial neoplasia, and adenocarcinoma: association with gleason score and chromosome $8 \mathrm{p}$ deletion. Cancer Res 2006;66:10683-10690
28. Gelmann EP, Steadman DJ, Ma J, Ahronovitz N, Voeller HJ, Swope S, Abbaszadegan M, Brown KM, Strand K, Hayes RB, Stampfer MJ. Occurrence of NKX3.1 C154T polymorphism in men with and without prostate cancer and studies of its effect on protein function. Cancer Res 2002;62:2654-2659

29. Guan B, Pungaliya P, Li X, Uquillas C, Mutton LN, Rubin $\mathrm{EH}$, Bieberich CJ. Ubiquitination by TOPORS regulates the prostate tumor suppressor NKX3.1. J Biol Chem 2008; 283:4834-4840

30. Bowen C, Stuart A, Ju JH, Tuan J, Blonder J, Conrads TP, Veenstra TD, Gelmann EP. NKX3.1 homeodomain protein binds to topoisomerase I and enhances its activity. Cancer Res 2007;67:455-464

31. Song LN, Bowen C, Gelmann EP. Structural and functional interactions of the prostate cancer suppressor protein NKX3.1 with topoisomerase I. Biochem J 2013;453:125-136

32. Padmanabhan A, Gosc EB, Bieberich CJ. Stabilization of the prostate-specific tumor suppressor NKX3.1 by the oncogenic protein kinase Pim-1 in prostate cancer cells. J Cell Biochem 2013;114:1050-1057

33. Aumüller G, Seitz J. Protein secretion and secretory processes in male accessory sex glands. Int Rev Cytol 1990;121: 127-231

34. Ayala AG, Ro JY, Babaian R, Troncoso P, Grignon DJ. The prostatic capsule: does it exist? Its importance in the staging and treatment of prostatic carcinoma. Am J Surg Pathol 1989;13:21-27

35. Raychaudhuri B, Cahill D. Pelvic fasciae in urology. Ann R Coll Surg Engl 2008;90:633-637

36. Lowsley OS. The development of the human prostate gland with reference to the development of other structures at the neck of the urinary bladder. Am J Anat 1912;13:299-349

37. McNeal JE. The zonal anatomy of the prostate. Prostate 1981;2:35-49

38. Cunha GR, Donjacour AA, Cooke PS, Mee S, Bigsby RM, Higgins SJ, Sugimura Y. The endocrinology and developmental biology of the prostate. Endocr Rev 1987;8:338362

39. Price D. Comparative aspects of development and structure in the prostate. Natl Cancer Inst Monogr 1963;12:1-27

40. Staack A, Donjacour AA, Brody J, Cunha GR, Carroll P. Mouse urogenital development: a practical approach. Differentiation 2003;71:402-413

41. Bhatia-Gaur R, Donjacour AA, Sciavolino PJ, Kim M, Desai N, Young P, Norton CR, Gridley T, Cardiff RD, Cunha GR, Abate-Shen C, Shen MM. Roles for Nkx3.1 in prostate development and cancer. Genes Dev 1999;13:966977

42. Tanaka M, Komuro I, Inagaki H, Jenkins NA, Copeland NG, Izumo S. Nkx3.1, a murine homolog of Ddrosophila bagpipe, regulates epithelial ductal branching and proliferation of the prostate and palatine glands. Dev Dyn 2000;219:248-260

43. Dutta A, Le Magnen C, Mitrofanova A, Ouyang X, Califano A, Abate-Shen C. Identification of an NKX3.1- 
G9a-UTY transcriptional regulatory network that controls prostate differentiation. Science 2016;352:1576-1580

44. Huang L, Pu Y, Alam S, Birch L, Prins GS. The role of Fgf10 signaling in branching morphogenesis and gene expression of the rat prostate gland: lobe-specific suppression by neonatal estrogens. Dev Biol 2005;278:396-414

45. Simons BW, Hurley PJ, Huang Z, Ross AE, Miller R, Marchionni L, Berman DM, Schaeffer EM. Wnt signaling though beta-catenin is required for prostate lineage specification. Dev Biol 2012;371:246-255

46. Francis JC, Thomsen MK, Taketo MM, Swain A. $\beta$-catenin is required for prostate development and cooperates with Pten loss to drive invasive carcinoma. PLoS Genet 2013;9:e1003180

47. Zhang TJ, Hoffman BG, Ruiz de Algara T, Helgason CD. SAGE reveals expression of Wnt signalling pathway members during mouse prostate development. Gene Expr Patterns 2006;6:310-324

48. Schaeffer EM, Marchionni L, Huang Z, Simons B, Blackman A, Yu W, Parmigiani G, Berman DM. Androgen-induced programs for prostate epithelial growth and invasion arise in embryogenesis and are reactivated in cancer. Oncogene 2008;27:7180-7191

49. Yu X, Wang Y, Jiang $M$, Bierie B, Roy-Burman $P$, Shen MM, Taketo MM, Wills M, Matusik RJ. Activation of beta-Catenin in mouse prostate causes HGPIN and continuous prostate growth after castration. Prostate 2009;69: 249-262

50. Mehta V, Schmitz CT, Keil KP, Joshi PS, Abler LL, Lin TM, Taketo MM, Sun X, Vezina CM. Beta-catenin (CTNNB1) induces Bmp expression in urogenital sinus epithelium and participates in prostatic bud initiation and patterning. Dev Biol 2013;376:125-135

51. Meeks JJ, Schaeffer EM. Genetic regulation of prostate development. J Androl 2011;32:210-217

52. Sciavolino PJ, Abrams EW, Yang L, Austenberg LP, Shen MM, Abate-Shen C. Tissue-specific expression of murine Nkx3.1 in the male urogenital system. Dev Dyn 1997;209: $127-138$

53. Wang X, Kruithof-de Julio M, Economides KD, Walker D, Yu H, Halili MV, Hu YP, Price SM, Abate-Shen C, Shen MM. A luminal epithelial stem cell that is a cell of origin for prostate cancer. Nature 2009;461:495-500

54. Bowen C, Bubendorf L, Voeller HJ, Slack R, Willi N, Sauter G, Gasser TC, Koivisto P, Lack EE, Kononen J, Kallioniemi OP, Gelmann EP. Loss of NKX3.1 expression in human prostate cancers correlates with tumor progression. Cancer Res 2000;60:6111-6115

55. Shen MM, Abate-Shen C. Molecular genetics of prostate cancer: new prospects for old challenges. Genes Dev 2010;24:1967-2000

56. Decker J, Jain G, Kießling T, Sander P, Rid M, Barth TTF, Möller P, Cronauer MV, Marienfeld RB. Loss of the tumor suppressor NKX3.1 in prostate cancer cells is induced by prostatitis related mitogens. J Clin Exp Oncol 2016;5:2

57. Le Magnen C, Virk RK, Dutta A, Kim JY, Panja S,
Lopez-Bujanda ZA, Califano A, Drake CG, Mitrofanova A, Abate-Shen C. Cooperation of loss of NKX3.1 and inflammation in prostate cancer initiation. Dis Model Mech 2018;11:dmm035139

58. Song H, Zhang B, Watson MA, Humphrey PA, Lim H, Milbrandt J. Loss of Nkx3.1 leads to the activation of discrete downstream target genes during prostate tumorigenesis. Oncogene 2009;28:3307-3319

59. Peng M, Deng J, Zhou S, Tao T, Su Q, Yang X, Yang X. The role of Clusterin in cancer metastasis. Cancer Manag Res 2019;11:2405-2414

60. Soloviev M, Esteves MP, Amiri F, Crompton MR, Rider CC. Elevated transcription of the gene QSOX1 encoding quiescin Q6 sulfhydryl oxidase 1 in breast cancer. PLoS One 2013;8:e57327

61. Dong JT. Chromosomal deletions and tumor suppressor genes in prostate cancer. Cancer Metastasis Rev 2001;20: 173-193

62. Emmert-Buck MR, Vocke CD, Pozzatti RO, Duray PH, Jennings SB, Florence CD, Zhuang Z, Bostwick DG, Liotta LA, Linehan WM. Allelic loss on chromosome 8p12-21 in microdissected prostatic intraepithelial neoplasia. Cancer Res 1995;55:2959-2962

63. Akamatsu S, Takata R, Ashikawa K, Hosono N, Kamatani N, Fujioka T, Ogawa O, Kubo M, Nakamura Y, Nakagawa H. A functional variant in NKX3.1 associated with prostate cancer susceptibility down-regulates NKX3.1 expression. Hum Mol Genet 2010;19:4265-4272

64. Dahia PL. PTEN, a unique tumor suppressor gene. Endocr Relat Cancer 2000;7:115-129

65. Suzuki H, Freije D, Nusskern DR, Okami K, Cairns P, Sidransky D, Isaacs WB, Bova GS. Interfocal heterogeneity of PTEN/MMAC1 gene alterations in multiple metastatic prostate cancer tissues. Cancer Res 1998;58:204-209

66. Kim MJ, Cardiff RD, Desai N, Banach-Petrosky WA, Parsons R, Shen MM, Abate-Shen C. Cooperativity of Nkx3.1 and Pten loss of function in a mouse model of prostate carcinogenesis. Proc Natl Acad Sci U S A 2002;99: 2884-2889

67. Lei Q, Jiao J, Xin L, Chang CJ, Wang S, Gao J, Gleave ME, Witte ON, Liu X, Wu H. NKX3.1 stabilizes p53, inhibits AKT activation, and blocks prostate cancer initiation caused by PTEN loss. Cancer Cell 2006;9:367-378

68. Bowen C, Ostrowski MC, Leone G, Gelmann EP. Loss of PTEN accelerates NKX3.1 degradation to promote prostate cancer progression. Cancer Res 2019;79:4124-4134

69. Kos L, Chiang C, Mahon KA. Mediolateral patterning of somites: multiple axial signals, including Sonic hedgehog, regulate Nkx-3.1 expression. Mech Dev 1998;70:25-34

70. Tanaka M, Lyons GE, Izumo S. Expression of the Nkx3.1 homobox gene during pre and postnatal development. Mech Dev 1999;85:179-182

71. Schneider A, Brand T, Zweigerdt R, Arnold H. Targeted disruption of the Nkx3.1 gene in mice results in morphogenetic defects of minor salivary glands: parallels to glandular duct morphogenesis in prostate. Mech Dev 2000;95:163-174 
72. Treier M, Gleiberman AS, O'Connell SM, Szeto DP, McMahon JA, McMahon AP, Rosenfeld MG. Multistep signaling requirements for pituitary organogenesis in vivo. Genes Dev 1998;12:1691-1704

73. Miyaguchi K, Uzawa N, Mogushi K, Takahashi K, Michikawa C, Nakata Y, Sumino J, Okada N, Mizushima H, Fukuoka Y, Tanaka H. Loss of NKX3-1 as a potential marker for an increased risk of occult lymph node metastasis and poor prognosis in oral squamous cell carcinoma. Int J Oncol 2012;40:1907-1914

74. Takada N, Nishida H, Oyama Y, Kusaba T, Kadowaki H, Arakane M, Wada J, Urabe S, Daa T. Immunohistochemical reactivity of prostate-specific markers for Salivary duct carcinoma. Pathobiology 2020;87:30-36

75. Patel MS, Bowen DK, Tassone NM, Gould AD, Kochan KS, Firmiss PR, Kukulka NA, Devine MY, Li B, Gong EM, Dettman RW. The homeodomain transcription factor Nkx3.1 modulates bladder outlet obstruction induced fibrosis in mice. Front Pediatr 2019;7:446

76. Qian D, Zheng W, Chen C, Jing G, Huang J. Roles of CCNB2 and NKX3-1 in nasopharyngeal carcinoma. Cancer Biother Radiopharm 2020;35:208-213

77. Abate-Shen C, Shen MM. Molecular genetics of prostate cancer. Genes Dev 2000;14:2410-2434

78. English HF, Santen RJ, Isaacs JT. Response of glandular versus basal rat ventral prostatic epithelial cells to androgen withdrawal and replacement. Prostate 1987;11:229242

79. Evans GS, Chandler JA. Cell proliferation studies in the rat prostate: II. The effects of castration and androgen-induced regeneration upon basal and secretory cell proliferation. Prostate 1987;11:339-351

80. Sugimura Y, Cunha GR, Donjacour AA. Morphological and histological study of castration-induced degeneration and androgen-induced regeneration in the mouse prostate. Biol Reprod 1986;34:973-983

81. Wang ZA, Shen MM. Revisiting the concept of cancer stem cells in prostate cancer. Oncogene 2011;30:1261-1271

82. Germann M, Wetterwald A, Guzmán-Ramirez N, van der Pluijm G, Culig Z, Cecchini MG, Williams ED, Thalmann GN. Stem-like cells with luminal progenitor phenotype survive castration in human prostate cancer. Stem Cells 2012; 30:1076-1086

83. Clark AK, Taubenberger AV, Taylor RA, Niranjan B, Chea ZY, Zotenko E, Sieh S, Pedersen JS, Norden S, Frydenberg M, Grummet JP, Pook DW; Australian Prostate Cancer BioResource, Stirzaker C, Clark SJ, Lawrence MG, Ellem SJ, Hutmacher DW, Risbridger GP. A bioengineered microenvironment to quantitatively measure the tumorigenic properties of cancer-associated fibroblasts in human prostate cancer. Biomaterials 2013;34:4777-4785

84. Federer-Gsponer JR, Müller DC, Zellweger T, Eggimann M, Marston K, Ruiz C, Seifert HH, Rentsch CA, Bubendorf L, Le Magnen C. Patterns of stemness-associated markers in the development of castration-resistant prostate cancer. Prostate 2020;80:1108-1117
85. Adisetiyo H, Liang $M$, Liao CP, Jeong JH, Cohen MB, Roy-Burman P, Frenkel B. Dependence of castration-resistant prostate cancer (CRPC) stem cells on CRPC-associated fibroblasts. J Cell Physiol 2014;229:1170-1176

86. Mai T, Markov GJ, Brady JJ, Palla A, Zeng H, Sebastiano $\mathrm{V}$, Blau HM. NKX3-1 is required for induced pluripotent stem cell reprogramming and can replace OCT4 in mouse and human iPSC induction. Nat Cell Biol 2018;20:900-908

87. Takahashi K, Yamanaka S. Induction of pluripotent stem cells from mouse embryonic and adult fibroblast cultures by defined factors. Cell 2006;126:663-676

88. Takahashi K, Yamanaka S. A decade of transcription factor-mediated reprogramming to pluripotency. Nat Rev Mol Cell Biol 2016;17:183-193

89. Buganim Y, Faddah DA, Cheng AW, Itskovich E, Markoulaki S, Ganz K, Klemm SL, van Oudenaarden A, Jaenisch R. Single-cell expression analyses during cellular reprogramming reveal an early stochastic and a late hierarchic phase. Cell 2012;150:1209-1222

90. Menendez S, Camus S, Herreria A, Paramonov I, Morera LB, Collado M, Pekarik V, Maceda I, Edel M, Consiglio A, Sanchez A, Li H, Serrano M, Belmonte JC. Increased dosage of tumor suppressors limits the tumorigenicity of iPS cells without affecting their pluripotency. Aging Cell 2012;11:41-50

91. Velychko S, Adachi K, Kim KP, Hou Y, MacCarthy CM, Wu G, Schöler HR. Excluding Oct4 from Yamanaka cocktail unleashes the developmental potential of iPSCs. Cell Stem Cell 2019;25:737-753.e4

92. Li R, Liang J, Ni S, Zhou T, Qing X, Li H, He W, Chen J, Li F, Zhuang Q, Qin B, Xu J, Li W, Yang J, Gan Y, Qin D, Feng S, Song H, Yang D, Zhang B, Zeng L, Lai L, Esteban MA, Pei D. A mesenchymal-to-epithelial transition initiates and is required for the nuclear reprogramming of mouse fibroblasts. Cell Stem Cell 2010;7:51-63

93. Malik V, Glaser LV, Zimmer D, Velychko S, Weng M, Holzner M, Arend M, Chen Y, Srivastava Y, Veerapandian V, Shah Z, Esteban MA, Wang H, Chen J, Schöler HR, Hutchins AP, Meijsing SH, Pott S, Jauch R. Pluripotency reprogramming by competent and incompetent POU factors uncovers temporal dependency for Oct4 and Sox2. Nat Commun 2019;10:3477

94. Soufi A, Donahue G, Zaret KS. Facilitators and impediments of the pluripotency reprogramming factors' initial engagement with the genome. Cell 2012;151:994-1004

95. Ma X, Kong L, Zhu S. Reprogramming cell fates by small molecules. Protein Cell 2017;8:328-348

96. Kuan II, Liang KH, Wang YP, Kuo TW, Meir YJ, Wu SC, Yang SC, Lu J, Wu HC. EpEX/EpCAM and Oct4 or Klf4 alone are sufficient to generate induced pluripotent stem cells through STAT3 and HIF2 $\alpha$. Sci Rep 2017;7:41852

97. Bonizzi G, Cicalese A, Insinga A, Pelicci PG. The emerging role of p53 in stem cells. Trends Mol Med 2012;18:6-12

98. Wenzel PL, Wu L, de Bruin A, Chong JL, Chen WY, Dureska G, Sites E, Pan T, Sharma A, Huang K, Ridgway R, Mosaliganti K, Sharp R, Machiraju R, Saltz J, 
Yamamoto H, Cross JC, Robinson ML, Leone G. Rb is critical in a mammalian tissue stem cell population. Genes Dev 2007;21:85-97

99. Mosteiro L, Pantoja C, de Martino A, Serrano M. Senescence promotes in vivo reprogramming through p16INK4a and IL-6. Aging Cell 2018;17:e12711

100. Laurent LC, Ulitsky I, Slavin I, Tran H, Schork A, Morey R, Lynch C, Harness JV, Lee S, Barrero MJ, Ku S, Martynova M, Semechkin R, Galat V, Gottesfeld J, Izpisua Belmonte JC, Murry C, Keirstead HS, Park HS, Schmidt U, Laslett AL, Muller FJ, Nievergelt CM, Shamir R, Loring JF. Dynamic changes in the copy number of pluripotency and cell proliferation genes in human ESCs and iPSCs during reprogramming and time in culture. Cell Stem Cell 2011;8:106-118

101. Brady JJ, Li M, Suthram S, Jiang H, Wong WH, Blau HM. Early role for IL-6 signalling during generation of induced pluripotent stem cells revealed by heterokaryon RNA-Seq. Nat Cell Biol 2013;15:1244-1252

102. Kim MJ, Bhatia-Gaur R, Banach-Petrosky WA, Desai N, Wang Y, Hayward SW, Cunha GR, Cardiff RD, Shen MM, Abate-Shen C. Nkx3.1 mutant mice recapitulate early stages of prostate carcinogenesis. Cancer Res 2002;62:29993004

103. Jiang AL, Hu XY, Zhang PJ, He ML, Kong F, Liu ZF, Yuan HQ, Zhang JY. Up-regulation of NKX3.1 expression and inhibition of $\mathrm{LNCaP}$ cell proliferation induced by an inhibitory element decoy. Acta Biochim Biophys Sin (Shanghai) 2005;37:335-340

104. Zhang P, Liu W, Zhang J, Guan H, Chen W, Cui X, Liu Q Jiang A. Gene expression profiles in the PC-3 human prostate cancer cells induced by NKX3.1. Mol Biol Rep 2010;37:1505-1512

105. Song LN, Silva J, Koller A, Rosenthal A, Chen EI, Gelmann EP. The tumor suppressor NKX3.1 is targeted for degradation by DYRK1B kinase. Mol Cancer Res 2015;13:
913-922

106. Kim JB, Greber B, Araúzo-Bravo MJ, Meyer J, Park KI, Zaehres H, Schöler HR. Direct reprogramming of human neural stem cells by OCT4. Nature 2009;461:649-643

107. Kim JB, Sebastiano V, Wu G, Araúzo-Bravo MJ, Sasse P, Gentile L, Ko K, Ruau D, Ehrich M, van den Boom D, Meyer J, Hübner K, Bernemann C, Ortmeier C, Zenke M, Fleischmann BK, Zaehres H, Schöler HR. Oct4-induced pluripotency in adult neural stem cells. Cell 2009;136:411419

108. Tsai SY, Bouwman BA, Ang YS, Kim SJ, Lee DF, Lemischka IR, Rendl M. Single transcription factor reprogramming of hair follicle dermal papilla cells to induced pluripotent stem cells. Stem Cells 2011;29:964-971

109. Wu T, Wang H, He J, Kang L, Jiang Y, Liu J, Zhang Y, Kou Z, Liu L, Zhang X, Gao S. Reprogramming of trophoblast stem cells into pluripotent stem cells by Oct4. Stem Cells 2011;29:755-763

110. Gao Y, Chen J, Li K, Wu T, Huang B, Liu W, Kou X, Zhang Y, Huang H, Jiang Y, Yao C, Liu X, Lu Z, Xu Z, Kang L, Chen J, Wang H, Cai T, Gao S. Replacement of Oct4 by Tetl during iPSC induction reveals an important role of DNA methylation and hydroxymethylation in reprogramming. Cell Stem Cell 2013;12:453-469

111. Heng JC, Feng B, Han J, Jiang J, Kraus P, Ng JH, Orlov YL, Huss M, Yang L, Lufkin T, Lim B, Ng HH. The nuclear receptor $\mathrm{Nr} 5 \mathrm{a} 2$ can replace Oct4 in the reprogramming of murine somatic cells to pluripotent cells. Cell Stem Cell 2010;6:167-174

112. Shi Y, Do JT, Desponts C, Hahm HS, Schöler HR, Ding $\mathrm{S}$. A combined chemical and genetic approach for the generation of induced pluripotent stem cells. Cell Stem Cell 2008;2:525-528

113. Bowen C, Gelmann EP. NKX3.1 activates cellular response to DNA damage. Cancer Res 2010;70:3089-3097 